
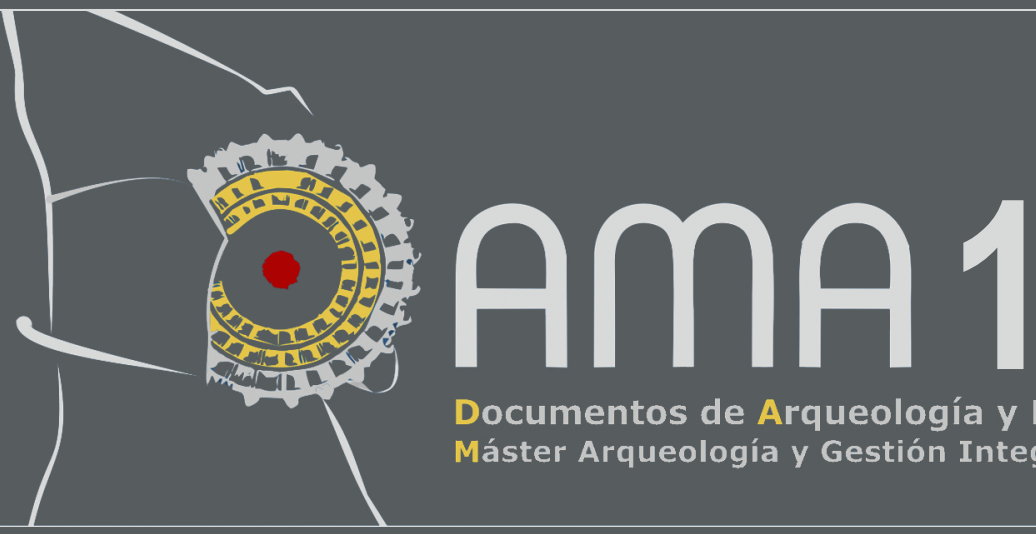

Documentos de Arqueología y Patrimonio Histórico

Máster Arqueología y Gestión Integral del Patrimonio de la Universidad de Alicante

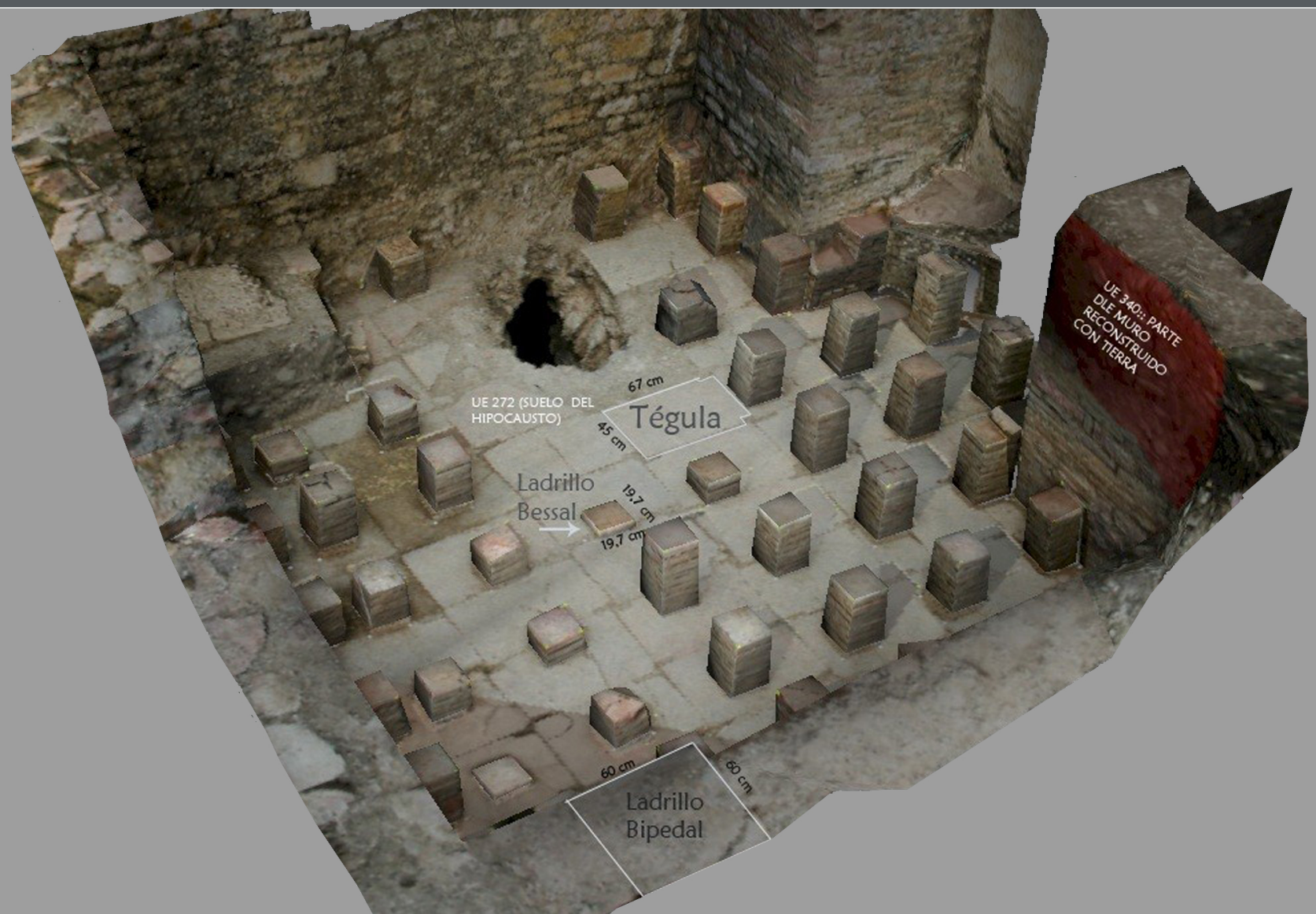

Documentos de Arqueología y Patrimonio Histórico Revista del Máster Universitario en Arqueología Profesional y Gestión integral del Patrimonio 



\section{DAMA 1}

\section{6}

DOCUMENTOS DE ARQUEOLOGÍA Y PATRIMONIO HISTÓRICO DEL MÁSTER UNIVERSITARIO EN ARQUEOLOGÍA PROFESIONAL Y GESTIÓN INTEGRAL DEL PATRIMONIO DE LA UNIVERSIDAD DE ALICANTE 


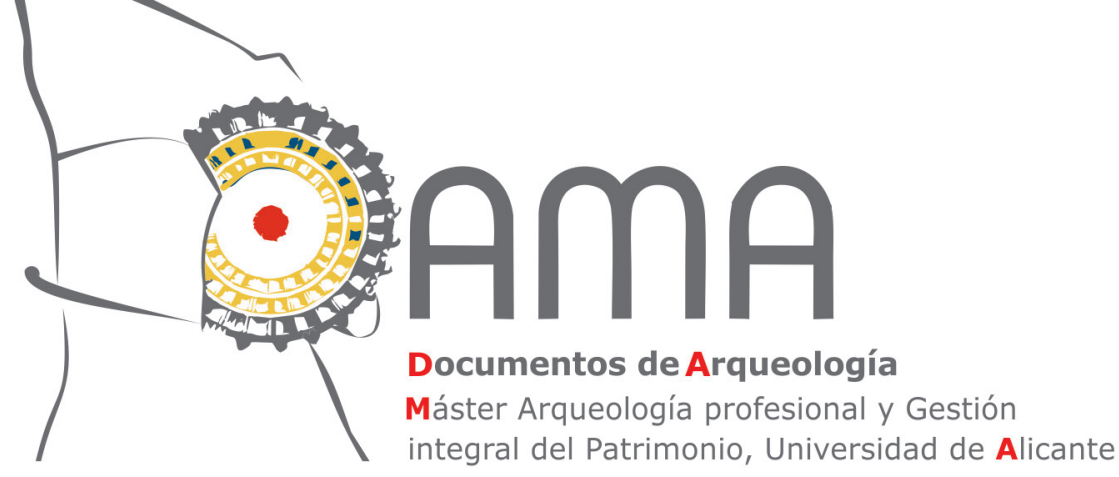

La revista electrónica DAMA. Documentos de Arqueología y Patrimonio Histórico surge como servicio para todos aquellos alumnos del Máster en Arqueología Profesional y Gestión Integral del Patrimonio de la Universidad de Alicante que se están iniciando en la investigación y cuya primera aportación a nuestra disciplina suele ser su Trabajo de Fin de Máster (TFM). Estos proyectos en muchos casos representan casi todo un curso de trabajo y esfuerzo, y con frecuencia quedan inéditos.

El objetivo de esta revista es ofrecer un medio que facilite la publicación de los resultados de sus TFM. La edición se presenta en versión digital y cuenta con su correspondiente ISSN. Se publica de forma anual en el sitio web de la Universidad de Alicante (http://web.ua.es/es/dama/) y en su repositorio (RUA). Los artículos publicados son descargables en formato PDF.

\section{Consejo de Redacción}

Directores (Coordinadores del Máster)

Carolina Doménech Belda

Fernando Prados Martínez

\section{Secretaria de Edición}

Julia Sarabia Bautista

\section{Vocales}

Los miembros de la Comisión Académica del Máster Universitario en Arqueología Profesional y Gestión del Patrimonio (http://dprha.ua.es/es/magip/comision-academica.html)

\section{Edita}

Máster Universitario en Arqueología Profesional y Gestión Integral del Patrimonio Departamento de Prehistoria, Arqueología, Historia Antigua, Filología Griega y Filología Latina

Facultad de Filosofía y Letras II

Universidad de Alicante

Ctra San Vicente del Raspeig s/n

E-03690 San Vicente del Raspeig (Alicante)

Web:http://dprha.ua.es

Teléfono: (+34) 965903663

Fax: (+34) 965903823

E-mail: revista.dama@ua.es

\section{ISSN}

$2530-2345$

\section{Portada}

Modelo fotogramétrico de un hypocaustum romano realizado por Ana Charquero 
EDITORIAL

Coordinación del máster

ENTREVISTA A SOLVEIG NORDSTRÖM: UNA MIRADA HACIA EL PASADO DE LA ESCUERA

Raúl Berenguer González ..

\section{ARQUEOLOGÍA Y MÉTODO}

EL ESTUDIO DE LOS MATERIALES CONSTRUCTIVOS DE TIERRA DEL CABEZO DEL POLOVAR (VILLENA, ALICANTE): APORTACIÓN A LAS FORMAS CONSTRUCTIVAS DE DOS PEQUEÑAS EDIFICACIONES CAMPESINAS DE LA EDAD DEL BRONCE EN EL LEVANTE PENINSULAR

María Pastor Quiles

VIVIENDAS POSTALAYÓTICAS: UNA APROXIMACIÓN A LOS ESPACIOS DOMÉSTICOS EN EL ARCHIPIÉLAGO BALEAR (550-123 ANE)

Octavio Torres Gomáriz

LAS FLOTAS DE GUARNICIÓN ROMANA EN LAS COSTAS DE HISPANIA A PARTIR DE LAS FUENTES EPIGRÁFICAS

Sergio Lledó Ramírez

UNA APROXIMACIÓN A LA RECONSTRUCCIÓN DEL PAISAJE HISTÓRICO: EL PROYECTO L'ALMISSERÀ Diana López Arroyo

NUEVAS PERSPECTIVAS PARA EL ESTUDIO ARQUEOLÓGICO DEL POBLAMIENTO RURAL MEDIEVAL EN ASPE (ALICANTE): HUERTAS Y ALQUERÍAS JUNTO AL RÍO TARAFA

Felipe Mejías López

ARQUEOLOGÍA DE LAS GUERRAS CARLISTAS

Iván Roldán Vergarachea

LA CERÁMICA DE USO ARQUITECTÓNICO EN NOVELDA: LA AZULEJERÍA DE FINALES DEL SIGLO XIX Y PRINCIPIOS DEL XX

Natalia Sala Pérez

PRÁCTICA Y USOS DE LA FOTOGRAMETRÍA DIGITAL EN ARQUEOLOGÍA

Ana $M^{a}$ Charquero Ballester.

\section{GESTIÓN Y PUESTA EN VALOR DEL PATRIMONIO}

ARQUEÓLOGOS CON DISCAPACIDAD. ARQUEOLOGÍA INCLUSIVA

Ana Samaniego Espinosa

"LES COVES DELS PESCADORS DE EL CAMPELLO": PROPUESTA DE RECUPERACIÓN, PUESTA EN VALOR Y USO PÚBLICO DE UN PATRIMONIO OLVIDADO

Ana Isabel Castro Carbonell .

LA COLONIA DE SANTA EULALIA. ESTUDIO Y PROPUESTA DE RECUPERACIÓN

Héctor de Arriba González

PROYECTO DE PUESTA EN VALOR DE LOS RESTOS DE LA GUERRA CIVIL EN LA CIUDAD DE ALICANTE

Leticia Victoria González Chouciño

ANTEPROYECTO MUSEOGRÁFICO DEL MUSEO DE HISTORIA DE SAX

Alberto Ochoa García

EL CONGRESO DE MÁSTER: UNA PROPUESTA DIDÁCTICA DEL MÁSTER DE ARQUEOLOGÍA DE LA UNIVERSIDAD DE ALICANTE

Ignasi Grau Mira, Sonia Gutiérrez Lloret, Carolina Doménech Belda, Julia Sarabia Bautista 



\title{
ARQUEOLOGÍA DE LAS GUERRAS CARLISTAS
}

\author{
Iván Roldán Vergaraechea
}

\section{RESUMEN}

Ante la mayor presencia estos últimos años de la arqueología contemporánea, ha permitido el inicio de otras arqueologías a fines a su contexto, pero totalmente dispersos en la temática. De modo que como no podía ser de otra forma, las guerras civiles carlistas del siglo XIX se han materializado hoy en lo que viene a denominarse como Arqueología de las Guerras Carlistas. Esta nueva línea de investigación, nace por la necesidad de dar nuevos enfoques que cuestionen a la historiografía tradicional del carlismo y ante falta de iniciativas sobre su evidente patrimonio totalmente abandonado. De modo que en las siguientes líneas presentaremos sus antecedentes hasta su situación actual, pasando por el análisis del patrimonio de las guerras carlistas hasta su devenir en los próximos años.

Palabras clave: Arqueología de las Guerras Carlistas, Patrimonio olvidado, Metodología, Situación Actual, Futuro

\section{ABSTRACT}

Given the increased presence in recent years of contemporary archeology, it has allowed the start of archaeologies other end to its context, but totally scattered in the subject. So how could it be otherwise, the civil wars of the nineteenth century carlist have materialized today in what comes to be called Archaeology of the Carlist Wars. This new line of research, is born by the need for new approaches that challenge the traditional historiography of the carlist and lack of initiatives to its obvious heritage completely abandoned. So in the following lines we will present their history to their current situation, through analysis of the heritage of the Carlist Wars to its evolution in the coming years.

Key words: Archaeology of the Carlist War, Forgotten heritage, Methodology, Current situation, Future 


\section{ANTECEDENTES}

En un comienzo, los primeros trabajos relacionados con la arqueología de los siglos XIX y XX, dentro hoy de la Arqueología del Pasado Contemporáneo (González, 2014, p. 1683), se reducían a la búsqueda del registro material, para poder servir de ilustraciones a los trabajos documentales. En vez de intentar aportar algo de forma autónoma mediante la interpretación arqueológica, se consideraba una disciplina subordinada a la histórica (Renfrew y Bahn, 2008, pp. 100-104), por lo que su despegue de forma independiente ha sido bastante tardío.

En España, la aparición de la Arqueología del Pasado Contemporáneo vino de la mano de la Arqueología de la Guerra Civil Española desde inicios del siglo XXI. Aquí destacan las labores que el equipo de Alfredo González Ruibal viene realizando desde el año 2006 en diferentes puntos de la geografía española (González, 2016, p. 24). Es interesante ver cómo están siendo los conflictos más cercanos en el tiempo, los primeros en ser estudiados desde esta ciencia. Al parecer, son los sucesos bélicos más importantes del siglo XX los que más repercusión mediática tuvieron y tal vez, unido a que todavía estén entre nosotros varias de las generaciones que vivieron estas guerras, como la II Guerra Mundial, hayan provocado que la arqueología en un primer momento se centrase en su estudio.

En todo esto ha influido mucho el desarrollo de la Arqueología del Conflicto, que ya una vez finalizada la II Guerra Mundial provocó cierto interés hacia los restos materiales por parte de algunos investigadores. Al comienzo, básicamente se trataba de describir búnkeres y otros tipos de restos de guerra. Pero, ante el auge del pensamiento postmoderno y sus repercusiones en la arqueología postprocesual, surgió un interés por el sujeto, y por lo tanto, se pasó de un trabajo de carácter descriptivo, a uno más profundo en el que había que interpretar lo sucedido. Por lo que hoy en día, gracias a los avances teóricos y metodológicos, se ha articulado un discurso material y arqueológico sobre el conflicto (VV.AA, 2015, pp. 12-13).

Acercándonos cada vez más a nuestro objeto de estudio, en sí, el análisis del "conflicto" es multitemporal, ya que entendemos que en todas las épocas se han generado restos materiales de diferentes conflictos (VV.AA, 2015, p. 10). A los cuales debemos de añadir que generalmente se ha empezado estudiando los restos de la guerra o derivado de ellos. Otra vez, para el caso de la Arqueología de la Guerra Civil Española: fortificaciones, campos de batalla, fosas comunes y centros de detención y/o concentración (Ayán, 2015, p. 31).

Siguiendo el hilo, los estudios recientes que se están desarrollando dentro de estas arqueologías del pasado contemporáneoy del conflicto, nos encontramos anteun paréntesis en el que si tradicionalmente la arqueología comenzó estudiando los periodos más antiguos, hasta la época medieval; hemos dado un salto inverso comenzando ahora con el estudio de los contextos más contemporáneos, hacia los menos actuales. Esto está acarreando la aparición de otras subdisciplinas de estudio como es el que se presenta a continuación: la Arqueología de las Guerras Carlistas. Al igual que ocurre con la Guerra Civil Española, por la necesidad de estudiar no tanto los sucesos bélicos y la gloria de determinados personajes; sino más bien por todo lo contrario, analizar el resto de los involucrados, es decir, la sociedad. En otras palabras, pasar de la visión parcial, sesgada y elitista que nos ha proporcionado las fuentes escritas, a una más objetiva a través de la documentación arqueológica, para poder llegar a conocer de mejor manera a la sociedad implicada (Roldán y Escribano, 2015, p. 146). 


\section{SITUACIÓN ACTUAL}

Centrándonos más en el carlismo, existe una gran dicotomía entre el estudio de lo material y el realizado a partir de la documentación escrita. Esta diferencia se ve claramente por la copiosa bibliografía que se ha generado en un corto periodo de tiempo, debido al interés que la ha creado. Como afirmaron M. C. Rubio y M. Talavera en su cuaderno bibliográfico: “...la historiografía del carlismo, recoge 2059 referencias de las monografías, compilaciones, artículos de revista, actas de congresos y tesis doctorales publicados entre 1973 y 2005" (Rubio y Talavera, 2007, p. 11). Pero a pesar de haber creado un conocimiento importantísimo sobre la historia del carlismo, son pocas las iniciativas que se han desarrollado desde nuestra disciplina arqueológica. Dichas iniciativas se han caracterizado por su breve puntualidad, por su naturaleza diversa y por su dispersión a nivel geográfico.

En una primera síntesis realizada sobre el estado de las investigaciones en la Comunidad Foral de Navarra y la Comunidad Autónoma Vasca, los resultados hablan por sí solos (Roldán y Escribano, 2015, pp. 134-135):

Para el caso de Navarra, hasta el año 2016 básicamente podíamos destacar dos actuaciones arqueológicas, cuyo objetivo no siendo tanto el estudio de las guerras del XIX, han aportado cierto conocimiento a la materia. Se trata de las excavaciones de los castillos medievales de Huarte y Monjardín, en donde el Gabinete de Arqueología Navark S.L. en sus campañas del 2005 pudo en ambos casos documentar parte de las estructuras de los fuertes que respectivamente albergaron durante las guerras carlistas y algo de los restos materiales que generaron.

Por lo demás, no ha sido hasta el año 2016 cuando finalmente hemos asistido al primer proyecto que tenía como objetivo propio el estudio arqueológico de un fuerte de la III Guerra Carlista (1872-1876). La campaña de excavación dentro del reducto conocido como Princesa de Asturias (Villatuerta), se desarrolló entre los días 16 y 27 de mayo, gracias al esfuerzo del Ayuntamiento deVillatuerta y el Grupo de Investigación en Patrimonio Construido (GPAC) de la Universidad del País Vasco (Fig. 1). Este ha representado el primer trabajo de esta índole en la Comunidad Foral de

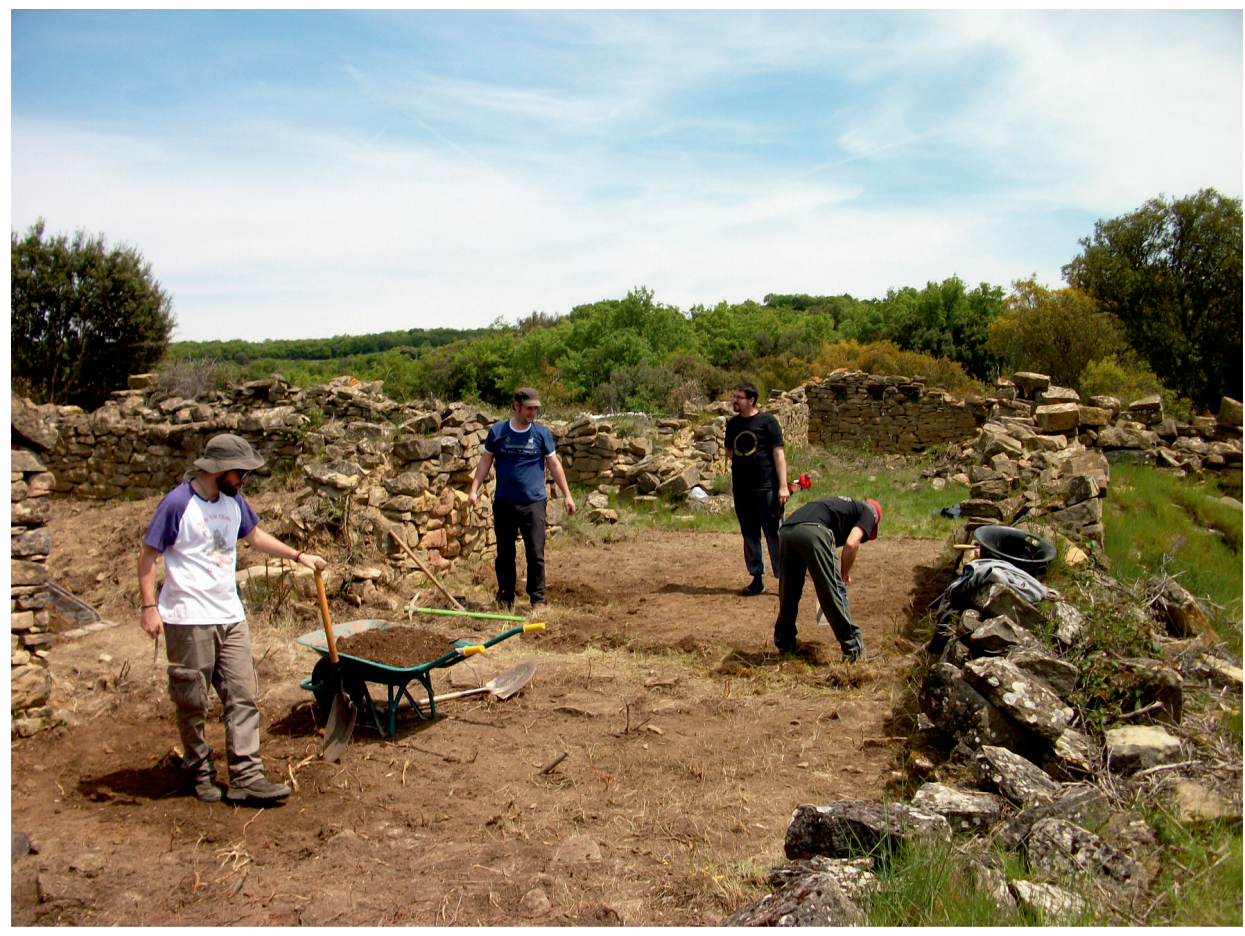

Fig. 1. Imagen del segundo día de campaña. Trabajando en el interior del fuerte. Foto propia.

Navarra, que busca en este caso llegar a conocer más sobre cómo eran los fuertes de campaña del siglo XIX, cómo vivían sus huéspedes y que tipo de actividades se desarrollaron en su interior. Es decir, un proyecto centrado en el análisis de la cotidianidad. 
La Comunidad Autónomo Vasca, en cambio, presenta un escenario algo más dinámico. Aun así, los estudios relacionados con el carlismo son escasos y su naturaleza varía de acuerdo a los objetivos de las intervenciones en las que se desarrollaron"

Por un lado, nos encontramos con trabajos que tratan sobre restos materiales de época carlista, pero no porque fueran objeto de estudio en sí mismos, sino como consecuencia de la búsqueda de objetos y estructuras de cronologías anteriores. Es el caso, por ejemplo, de algunas prospecciones para identificar materiales y estructuras de la Edad del Hierro (Olano, 1997, pp. 160-162), del estudio de la Muralla de la villa de Peñacerrada (Fernández, 2004, pp. 47-52), de San José de la Isla (Aníbarro, 2006, pp. 349-352; Aníbarro, 2007, pp. 375-380; y Aurrekoetxea, 2011, pp. 275-283), del castillo de Labastida (Quirós, 2014, pp. 83-87) o del monte San Bernabé (Martínez, 2015, pp. 266-270). Cabe señalar y destacar que en los citados estudios estos restos fueron considerados y estimados a pesar de su cronología reciente.

Por otro lado, están las intervenciones que, teniendo por objetivo el estudio de estructuras constructivas carlistas, se han centrado en la publicación exhaustiva de los restos hallados. Así sucede en la mayoría de los casos, como en el Fuerte de San Enrique (Rodríguez, 1986, pp. 53-55; Rodríguez, 1987, p. 46; y Urteaga, 2015, pp. 356-357), el Casco Arramendi (Benito, 2003, pp. 156-158; y Benito, 2004, pp. 151-152), el Alto de Lugaritz (Ayerbe, 2005, pp. 408-409), el Fuerte de Ametzagaina (García y Moraza, 2009, pp. 377-379), el Fuerte Zumalakarregi (Buces, 2012, pp. 321-324), la Fortificación de Atxetilun (Arrese, 2013, pp. 320-321) o el Fuerte Oriamendi (Moraza, 2013, pp. 278-283). Estos trabajos conforman una base informativa de primer nivel para estudios de caracterización y síntesis posteriores.

Por último, estarían aquellos estudios dirigidos a la época que planteamos, que han tratado de ir más allá del enfoque descriptivo y han aportado nueva información sobre el periodo. Dentro de este grupo, destacan los estudios de la Torre del telégrafo de Quintanilla (Sánchez, 2009, pp. 133-143; Sánchez, 2010, pp. 109-114), de los Fuertes de Arrontegi (Martínez, 2011, pp. 198-201), y Monte San Cristóbal (Martínez, 2013, pp. 56-60), así como la propuesta metodológica para la prospección en campo de batallas carlistas (Astorqui, 2013, pp. 214-218).

El vaciado de información historiográfica demuestra, por tanto, que el estudio arqueológico de las guerras civiles del siglo XIX no es un tema nuevo, al menos en la Comunidad Autónoma Vasca, pero que todavía no ha sido acometido de forma sistemática. La mayoría de trabajos se han desarrollado al amparo de las leyes de patrimonio o gracias a iniciativas particulares, y no como fruto de líneas de investigación centradas en el carlismo.

\section{EI PATRIMONIO DE LAS GUERRAS CARLISTAS}

\section{1. ¿En qué consiste?}

Mientras en otros periodos los restos arqueológicos puedan definirse por ser monumentales, artísticos, bellos o pensados para durar siglos, aquí prevalece como en otros conflictos, la funcionalidad sobre todos los criterios. El universo se simplifica a la guerra, por lo que lo más importante es: pasar inadvertido ante el enemigo, que las defensas sean lo más sólidas posibles, construidas en el menor tiempo y con los recursos disponibles. La vida de estas obras no estaba pensada para ir más allá que

1 Las investigaciones que a continuación se señalan, provienen de un vaciado de información realizado sobre la revista Arkeoikuska, en cuyas publicaciones se recogen todas las actuaciones arqueológicas efectuadas en CAPV desde 1983 en adelante. Por lo que resulta una clara referencia a la hora de matizar cuantas intervenciones relacionadas con las guerras carlistas se han hecho. 
la duración del propio conflicto, por lo que claramente se fundamentan en construcciones humildes y muy vulnerables al paso del tiempo. A esto debe sumarse la dificultad de encontrarse normalmente en zonas montañosas y alejadas de la urbe. Por lo que no resulta del todo fácil en la actualidad dar con estos vestigios, a pesar de las herramientas de que disponemos. Simplemente porque en muchos de los casos únicamente nos han quedado los restos de los movimientos de tierra, materializados en: fosos, trincheras y escarpas. Y ¿a qué nos referimos con restos? En orden de mayor envergadura a menor, podríamos citar: fuertes (o reductos), torres, baterías, extensas líneas de trincheras y los propios campos de batalla; por no hablar de los lugares a los que se les dará una nueva función para estos conflictos, como son: castillos, ermitas, iglesias, estaciones de ferrocarriles y los propios pueblos o ciudades, que durante la guerra se llegaron a convertir en verdaderas plazas-fuertes.

No obstante, dentro de esta amalgama de construcciones militares, son las ruinas de los fuertes decimonónicos tal vez los elementos más característicos en donde puedan simplificarse la evolución de la poliorcética (hasta finales del siglo XIX), siempre ante los avances del campo de la artillera. Por lo que merece la pena detenernos un instante en analizar estos fuertes, para comprender la naturaleza de los mismos.

\subsubsection{La morfología de los fuertes}

Los sistemas de fortificación abaluartados que alcanzaron su cenit durante el siglo XVIII, entraron en crisis a mediados del siglo XIX, una vez que las innovaciones pirobalísticas demostraron la ineficacia de estas defensas. El avance en artillería ${ }^{2}$ forzó un cambio, que supuso el reemplazo de los fuertes abaluartados, ya obsoletos, por campos atrincherados, en cuyas posiciones dominantes se establecían fuertes más pequeños con nuevos elementos: para su defensa contaban (entre otros) con traveses, que consistían en grandes cúmulos de tierra que protegían del impacto de granada a sus ocupantes; y como posiciones ofensivas, estaban dotadas de líneas de baterías para la contestación al fuego de artillería, a veces acasamatadas ${ }^{3}$ (Sáez, 2014, p. 103), (Martinena, 2014, pp. 27-29).

Claro está, que nunca fue lo mismo construir un fuerte en tiempos de guerra o de paz. Por lo que atendiendo al espacio temporal en el que nos encontremos, se ha determinado la existencia de tres tipos morfológicos de fortificación, que se prestan en función a las necesidades del momento (Clairac, 1884, pp. 156-164):

1. Fortificación de campaña: se ejecuta durante la guerra por medio de los mismos soldados que la defienden. En la mayoría de los casos, por medio de movimiento de tierras, auxiliadas algunas veces con madera que se usa para revestimientos, abrigos, caponeras, etc..., y son abandonadas cuando termina la guerra. Se distinguen tres elementos principales: el obstáculo, destinado a impedir la marcha del enemigo; la masa cubridora, que protege al defensor de los tiros del mismo, y el terraplén, por donde el defensor puede circular al abrigo del fuego. El obstáculo lo constituye el foso, cuyas dimensiones depende de la importancia de la obra; la masa cubridora el parapeto, cuya altura y espesor depende también de la naturaleza de la obra a que se aplica; y el terraplén en las obra de campaña se hace excavando una trinchera, con el objetivo de disminuir la altura del parapeto, haciendo que se termine el trabajo con más rapidez.

2 De proyectiles esféricos a cabezas ojivales, el rayado de las ánimas, la retrocarga, la aparición de cañones de acero, los cañones de tiro rápido.

3 Casamata: se utiliza este término para hacer referencia a la posición de artillería abovedada, que se encuentra totalmente protegida por todos sus costados. Únicamente tiene dos orificios: el primero para abrir fuego y el segundo detrás de la línea de cañón para que puedan trabajar los artilleros. 
2. Fortificación mixta o semipermanente: siempre que la importancia de las posiciones lo requiera, y no apremien las circunstancias, se dan mayores dimensiones y más fuerza a los perfiles de campaña, constituyendo fortificaciones semipermanentes, las cuales tienen por objeto principal el que no puedan ser atacadas con los recursos ordinarios que acompañan a los ejércitos en campaña, siendo necesario llevar ya el material que se requiere para los sitios.

En comparación con el de campaña, aumenta la altura del parapeto, para proporcionar mejor abrigo a las tropas. El foso debe ofrecer mayor obstáculo al enemigo, aumentando su profundidad y anchura. Esto requiere varias semanas de trabajo. En las obras mixtas hay que disponer de mayor número de emplazamientos para artillería, que es también de mayor calibre y toda su organización interior es mucho más completa que los de campaña. Lo que caracteriza a estas obras es el revestimiento de las escarpas y el flanqueo de los fosos por medio de caponeras; ambas de madera. Los trazados de estos fuertes son análogos a los de las obras permanentes, si bien sus dimensiones suelen ser algo menores que las de estos últimos, a menos que no exista la idea de convertirlos poco a poco en obras permanentes.

3. Fortificación permanente: establecidas en situación de importancia capital y constante para la defensa nacional, y disponiendo para su construcción de tiempo ilimitado, se utilizan en ella todos los recursos de que dispone la industria, para organizarlas y armarlas de modo que resistan a las fuertes piezas que constituyen la artillería de sitio. Caracteriza a estas obras permanentes el agregarse el camino cubierto. En los materiales, en vez de ser la tierra el principal, se emplean en gran proporción las mamposterías de diversas clases, y recientemente el uso del hierro y el acero, aunque todavía en casos excepcionales (Fig. 2).

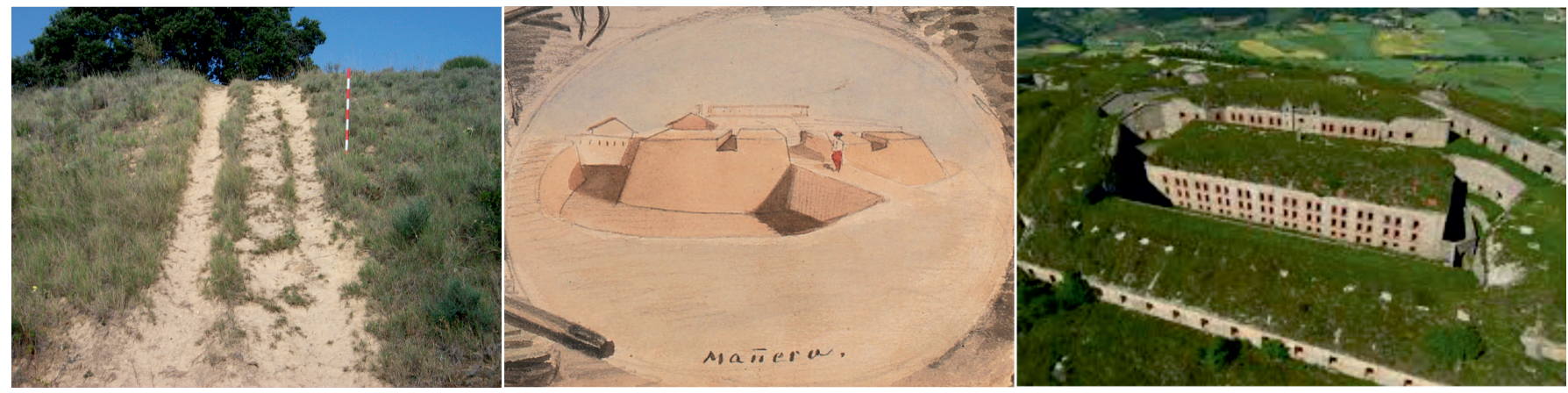

Fig. 2 (de izquierda a derecha): fuerte de campaña (Apalaz, Estella), foto propia; fuerte mixto (Santa Bárbara, Mañeru), del libro: Recuerdos de una Guerra Civil. Álbum del Bloqueo de Pamplona, de Ignacio J. Urrizelqui; fuerte permanente (San Cristóbal, Pamplona), http://www.navarra.es.

En criterios generales, los reductos anteriores a la III Guerra Carlista, fueron en esencia mucho más simples, de menores elementos defensivos y algo más pequeños, albergando menos instalaciones dentro de sus recintos, casi limitándose a la habitación para la tropa y un polvorín (Sáez, 2014, pp.100101). Mientras que durante ese tercer conflicto, abundaron más los de carácter mixto, contando con: caponeras, traveses, cuarteles, repuestos de municiones, aljibes, letrinas, habitación para los oficiales... Sin embargo, en el caso de los fuertes construidos por el bando carlista, desconocemos el nivel de sofisticación de sus obras, entre otras muchas razones por la casi inexistencia de planos cartográficos militares que nos hayan llegado hasta la actualidad (al contrario que en el bando liberal) y de las exiguas intervenciones arqueológicas desarrolladas en ellas, que nos ayudasen a arrojar más luz en su comprensión. 


\section{2. ¿Cómo estudiarlo?}

Básicamente el patrimonio de las guerras carlistas puede llegar a estudiarse a través de cuatro vías posibles:

\subsubsection{Las fuentes escritas}

Es en las fuentes primarias en donde quedan recogidos los sucesos bélicos de estas guerras. Sus narradores (generalmente militares de alta posición o civiles que presenciaron los altercados), cuentas las diferentes escaramuzas y enfrentamientos que padecieron. De modo que, a pesar de ser lecturas en forma de diarios de campo, colateralmente siempre aportan información de las ubicaciones de sus posiciones y las de sus enemigos, a veces incluso con detalles que nos brindan la ocasión de tener una breve descripción de las construcciones.

Al tratarse de un patrimonio contemporáneo, las fuentes escritas son una de las mejores herramientas que tenemos a nuestro alcance para poder llegar a comprender y estudiar las edificaciones que se llegaron a construir. No obstante, se trata de una realidad parcial, en la que únicamente la labor de la arqueología podrá corroborar finalmente hasta qué punto y que obras se generaron en dicho lugar.

Por citar algunos ejemplos, entre las narraciones más relevantes destacan: Apuntes para la Campaña del Primer Cuerpo del Ejército del Norte. Según el diario del comandante de ingenieros liberal, Ángel Rodríguez de Quijano y Arroquia, en cuyo trabajo narra su paso por Navarra entre los años 1874 y 1876. Los libros escritos por los militares carlistas: Antonio Brea, en su Campaña del Norte de 1873 a 1876; o el de Francisco Hernando, en La Campaña Carlista (1872-1876). Una referencia imprescindible son las recopilaciones realizadas por el Cuerpo del Estado Mayor del Ejército en su Narración Militar de la Guerra Carlista de 1869 a 1876. Y finalmente la obra de Antonio Pirala Historia Contemporánea. Segunda parte de la guerra Civil. Anales desde 1843 hasta el fallecimiento de Alfonso XII.

La prensa de la época es otra fuente menos usada, pero que resulta muy importante gracias a las valiosas aportaciones realizadas por los corresponsales de guerra enviados a estos conflictos. Del bando carlista tenemos el periódico oficial El Cuartel Real. Del liberal son muchos los periódicos que nos informan, repitiendo la información de los demás ya que la noticia se pagaba. Entre los periódicos más importantes destacan: El Imparcial, El Globo, La Ilustración Española y Americana, El Siglo Futuro, o La Epoca. Unido a estos tenemos otros memoriales que son importantes, como es el Memorial de Ingenieros y Revista Científico Militar, que analizará ciertos momento de esta guerra civil desde un punto de vista militar una vez finalizada.

\subsubsection{Las fuentes gráficas}

Otra fuente de gran valor son las fuentes gráficas. Aquí se recogen imágenes de las fortificaciones, que resultan ser en muchos casos la única evidencia que nos llega de la forma de algunos recintos. En el libro de Recuerdos de una Guerra Civil. Álbum del Bloqueo de Pamplona de Ignacio J. Urrizelqui, se pueden encontrar numerosas acuarelas y bocetos de fuertes de ambos bandos. Sin embargo, debemos de recordar que aunque en la mayoría de los casos sus dibujantes se tratan de militares o entendedores del arte militar, esta fuente debe tratarse con cautela, por no saber el nivel de fidelidad acorde a la realidad expresada en cada obra por el autor.

Además contamos con cartografía militar hecha por el ejército liberal de torres y fuertes que nos son vitales hoy para poder estudiarlos en los casos de los que disponemos de ellos. Esta documentación proviene del Instituto de Historia y Cultura Militar del Ejército de Tierra (IHCMET). 


\subsubsection{Las fuentes Orales}

Muchas veces se termina de recoger información relevante gracias a los recuerdos que en los pueblos se ha mantenido en la memoria colectiva. Generalmente son datos que en ocasiones contradicen a las fuentes oficiales y que pueden llegar a ser muy enriquecedoras para cualquier investigación arqueológica contemporánea.

\subsubsection{Las fuentes arqueológicas}

Como en el siguiente apartado veremos, el patrimonio bélico del siglo XIX se encuentra tremendamente afectado. Es por eso que a nivel arqueológico y gracias a los avances tecnológicos de estos últimos años, podemos decir que la arqueología puede servirse de forma casi autónoma para inventariar y catalogar los restos de estos bienes. De forma que se ha convertido en una fuente primordial tan importante como la escrita. Más aun, cuando no disponemos de casi información sobre las construcciones carlista, quedándonos a veces únicamente con las aportaciones arqueológicas para su documentación.

1. La Teledetección: estas nuevas herramientas a las que nos referíamos, se engloban dentro de lo que hoy en día se ha querido denominar como "teledetección". Según lo define el Instituto Geográfico Nacional (IGN): es la técnica de adquisición de datos de la superficie terrestre desde sensores instalados en plataformas espaciales. La interacción electromagnética entre el terreno y el sensor, genera una serie de datos que son procesados posteriormente para obtener información interpretable de la Tierra (https://www.ign.es/ign/layoutIn/teledeteccionQueEs.do).

De modo que hoy en día, gracias a la disponibilidad de imágenes vía satélite y el desarrollo de nuevas tecnologías, la teledetección es una herramienta de trabajo más que pude aplicarse a la investigación arqueológica. Consiste en la interpretación de anomalías en el terreno que puedan verse a través de los visores geográficos como SITNA (Sistema de Información Territorial de Navarra), GeoEuskadi (para el caso de la CAPV), o IBERPIX (del IGN). Estos visores permiten, a la vez generar ortofotos de años actuales de la zona de interés, y analizar los vuelos históricos que se realizaron durante el siglo anterior, para poder seguir investigando la evolución del terreno en busca de las anomalías que nos hablarían del presunto yacimiento. Otra vez más, centrándonos en la Comunidad Foral de Navarra, las primeras ortofotos históricas provienen de los vuelos realizados por el aviador estellés Julio Ruiz de Alda Miquélez del año 1929, por encargo de la Diputación Foral de Navarra. De forma que son unas imágenes bastante cercanas a los sucesos bélicos del siglo anterior, que sin duda ayudan muchísimo en la localización y descripción de los restos (Figs. 3-5). Para el caso de la Comunidad Autónoma Vasca, las primeras ortofotos históricas responderían al vuelo americano de 1945/46 (también conocidos como Serie A) que se realizó a lo largo y ancho de la geografía española (Figs. 4-5).

2. La Toponimia: unido a estas ortofotos, otra de las técnicas que tenemos para desarrollar un mejor trabajo, es el uso de la toponimia que en la actualidad podemos encontrar en todos estos visores comentados en forma de aplicación temática. Para el caso carlista, han quedado en la memoria local, la impronta de ciertos topónimos que hacen referencia a lugares fortificados o campos de batalla, que en algunos casos resultan ser bastante generalizados para el vasto territorio en donde se sucedieron los conflictos. He realizado un vaciado de información de los topónimos más habituales en la Comunidad Foral de Navarra por medio de la empresa TRACASA, que mediante su página web (http://toponimianavarra.tracasa.es/) de toponimia oficial de Navarra, permite buscar cualquier topónimo que queramos conocer y ubicar. De partida, en un estudio anterior introduje varios topónimos que se asocian a esta cronología: fuerte, cañón o trinchera. Y probé suerte con otros que podrían darme más información: reducto, batería, polvorín, foso, parapeto, artillería, telégrafo y batalla. El resultado inmediato fue espectacular: Con uno de los topónimos que ya conocía que se 
vincula a estas guerras "fuerte", tras realizar un primer filtrado y ver cuales no podían servir (tras ser analizados metódicamente a través de los visores), fueron 24 los topónimos hallados, de entre los cuales varios se sabe de su localización como puntos militares durante el conflicto y otros nuevos que abren la oportunidad de hallar nuevos reductos que se escapan a las fuentes escritas. Como por ejemplo: Fuertezear (en Euskera: alrededor del fuerte. Municio de Alsasua), o Fuerte de la Somada (municipio de Arellano) (Fig. 3).

\begin{tabular}{|l|l|}
\hline \multicolumn{1}{|c|}{ Municipio } & \multicolumn{1}{c|}{ Toponimo } \\
\hline 1. Bearin & Alto del Fuerte \\
\hline 2. Facería 21 (monte Belástegui) & El Fuerte \\
\hline 3. Berrioplano & Fuerte Alfonso XII \\
\hline 4. Berrioplano & Carretera del Fuerte \\
\hline 5. Marcilla & Fuerte de los Moros \\
\hline 6. Lumbier & El Fuerte \\
\hline 7. Mendavia & El Fuerte \\
\hline 8. Erro & El Fuerte \\
\hline 9. Mañeru & El Fuerte \\
\hline 10. Echarri & El Fuerte \\
\hline 11. Cizur & El Fuerte \\
\hline 12. Cizur & El Fuerte (un segundo fuerte) \\
\hline 13. Esteribar & El Fuerte \\
\hline 14. Esteribar & Liecos del Fuerte \\
\hline 15. Arandigoyen & El Fuerte \\
\hline 16. Muru & El Fuerte \\
\hline 17. Dicastillo & El Fuerte \\
\hline 18. Ciriza & El Fuerte \\
\hline 19. Belascoáin & El Fuerte \\
\hline 20. Baztán & Fuertea (Euskera: el fuerte) \\
\hline 21. Alasasua & Fuertezear (Euskera: alrededor del fuerte) \\
\hline 22. Obanos & Fuerte de Infanta Isabel \\
\hline 23. Estella & Fuerte de San Millán \\
\hline 24. Arellano & Fuerte de la Somada \\
\hline & \\
\hline
\end{tabular}

Fig. 3: tabla con los 24 topónimos en Navarra que hacen referencia a la palabra de búsqueda "fuerte" y los respectivos municipios en donde se encuentran. Elaboración propia.

Fuertezear: la toponimia junto a la fotointerpretación han hecho posible localizar este pequeño fuerte situado a las afueras del pueblo de Alsasua, en una zona boscosa, que posiblemente hubiera sido complicado de haber dado con él de alguna otra forma. Teniendo en cuenta que en muchas ocasiones son restos de terraplenes que se han erosionado con el tiempo o ciertas trincheras colmatadas, para estas zonas espesas en vegetación resulta ser una de los mejores medios para su rastreo y localización. 

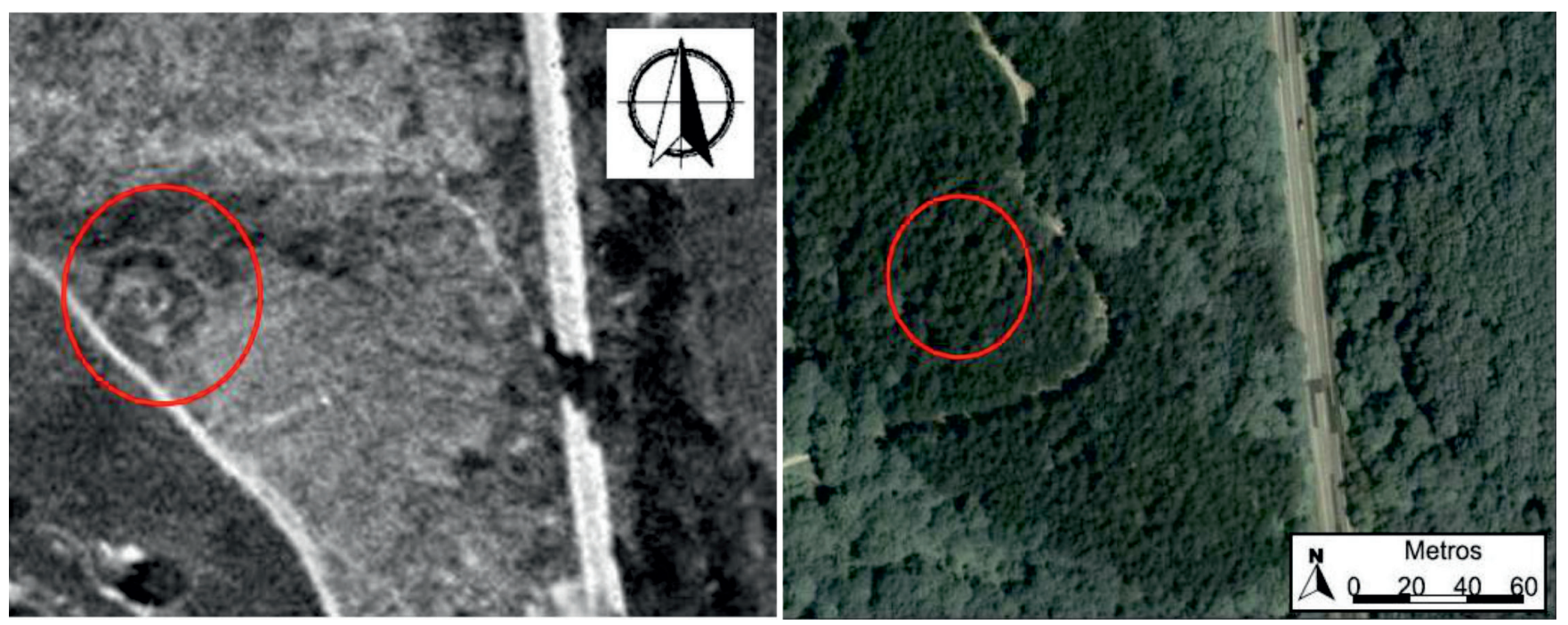

Fig. 4. (de izquierda a derecha): Ortofoto histórica del vuelo 1956-1957, del SITNA (Sistema de Información Territorial de Navarra), con la ubicación del fuerte; Ortofoto PNOA máxima actualidad, del IGN (Instituto Geográfico Nacional), con la señalización de la presunta ubicación del fuerte.
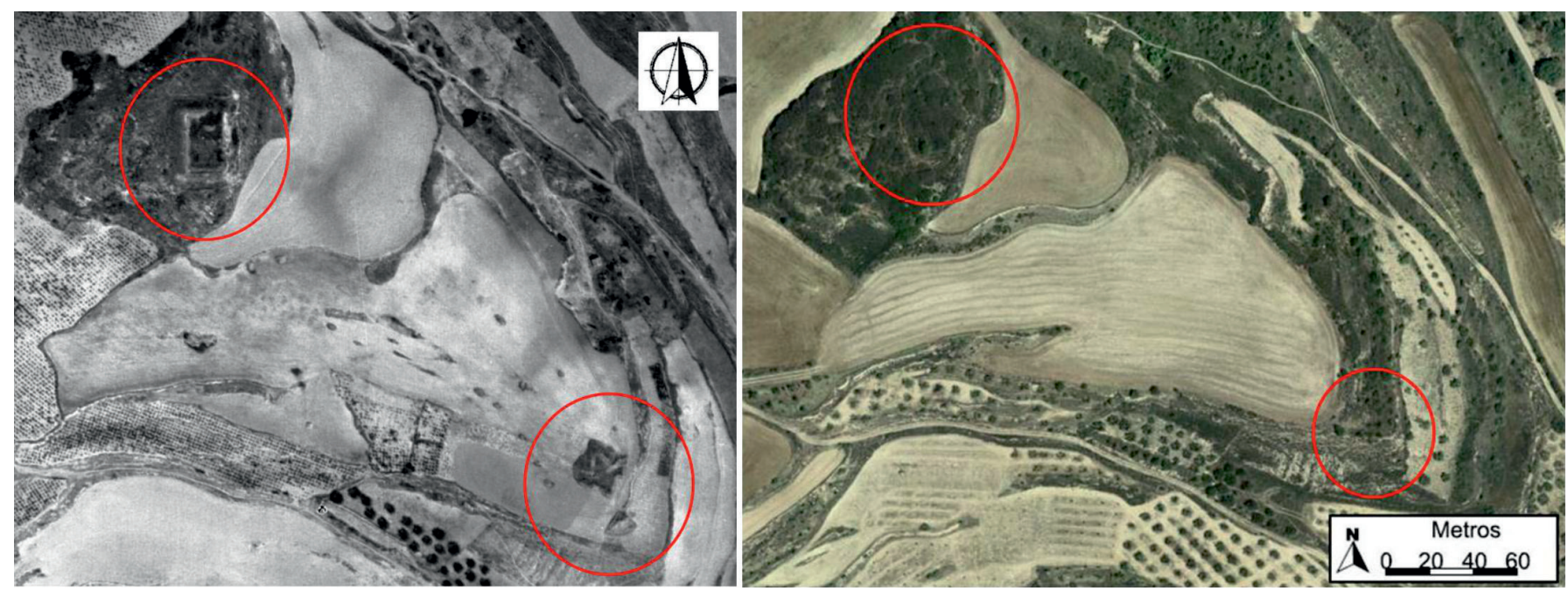

Fig. 5. (de izquierda a derecha): fuerte de la Somada y una posible posición de batería. Fotograma Np_29_117, del vuelo histórico de 1929-1931, del Servicio de Riqueza Territorial de Navarra; Ortofoto PNOA máxima actualidad, del IGN, con la señalización de la presunta ubicación de los restos.

Fuerte de la Somada: fuerte no documentado históricamente, pero si situado en las proximidades a los combates de la I y III Guerra Carlista. Desconocemos si se trata de un fuerte construido con anterioridad a las guerras carlistas o no. No obstante, su estudio es inédito. Posiblemente como el anterior, por ser posiciones carlistas de los cuales no ha llegado prácticamente información hasta la actualidad, en algunos casos más allá de la toponimia.

3. Imágenes LIDAR: Estos últimos años el desarrollo tecnológico de nuevos sistemas cartográficos han ayudado a la creación de las imágenes LIDAR (Laser Imaging Detection and Ranging), que aplicados a la arqueología, están convirtiéndose en una herramienta vital para la prospección en general y sobre todo para la centrada en zonas montañosas. Estas imágenes creadas a partir de una nube de puntos del terreno mediante un escáner laser aerotransportado (ALS), son capaces de crear 
modelos digitales de la elevación del terreno, eliminando la cubierta forestal. Por lo que todo resto arqueológico que mínimamente se intuya en el terreno, debería poder visualizarse. Pero para poder llegar a realizar imágenes LIDAR, es necesario la utilización de programas, como Global Mapper, que puedan abrir los formatos de archivo LAS, en los cuales se encuentra la información de los vuelos. Estos archivos se pueden descargar gratuitamente a través de la página del IGN.

Nuevamente, su aplicación a la localización de fuertes decimonónicos, es otra herramienta con la que podemos contar. Nos ayudará a vislumbrar cual es el estado actual del yacimiento que estamos investigando. Por poner un ejemplo claro, en la siguiente foto vemos a mano izquierda la localización de un fuerte liberal llamado Cáceres (Villaurta, Navarra) que se construyó sobre un castro de la Edad de Hierro (Fig. 6). El uso de los vuelos LIDAR han ayudado a crear una imagen en la que se aprecian los límites y forma del reducto.

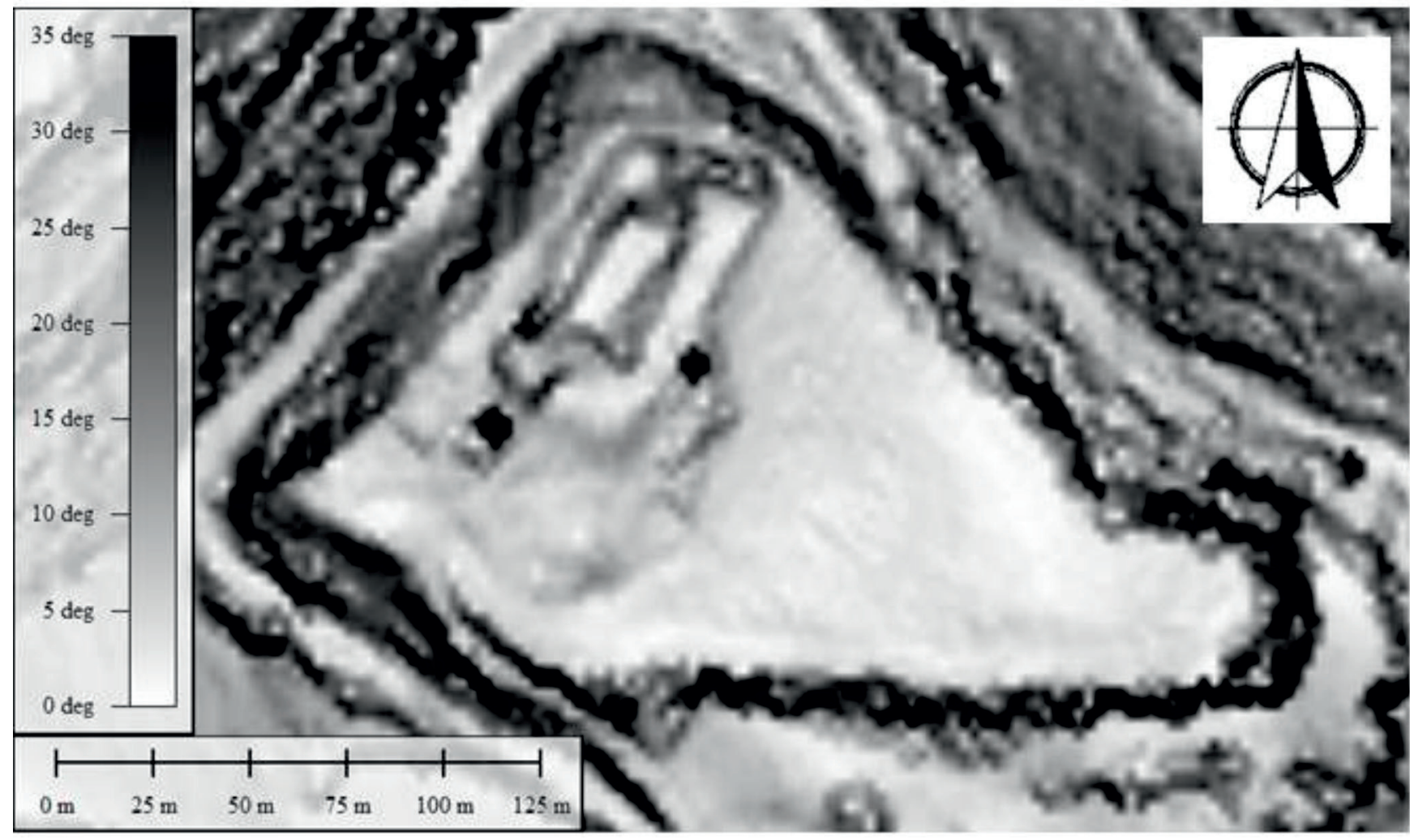

Fig. 6. Global Mapper 15, filtro SlopeShader sobre vuelo LIDAR (2x2 km). Se aprecia la delimitación del fuerte. Elaboración propia.

\section{3. ¿Cuál es su situación?}

En la Comunidad Foral de Navarra, y por extensión a la Comunidad Autónoma Vasca también, desde finales del siglo XVIII, hasta finales del siglo XIX, en tan solo 83 años, se dio una fase de construcción militar sin precedentes en la que se sucedieron hasta 5 guerras: La Guerra de la Convención (17931795), Las Guerras Napoleónicas (1808-1814), La Guerra Realista (1821-1823), La I Guerra Carlista (1833-1839) y La III Guerra Carlista (1872-1876). Tantos años de conflicto originaron cientos de fuertes en periodos de guerra, por lo que morfológicamente hablando respondieron a los modelos de reductos de campaña o semipermanentes. Se caracterizan por haberse edificado en posiciones dominantes sobre las principales poblaciones y vías de comunicación. Con ellos también se emplazaron cientos de baterías y kilómetros de líneas de trincheras (Arrieta, 2015, pp. 15-17). Como podemos imaginar, es un patrimonio vastísimo que como habíamos comentado anteriormente se encuentra 
en vías de desaparición. Lo demuestra el análisis evolutivo de las ortofotos desde 1929 o 1945, hasta la actualidad. Los cambios del uso del suelo cultivable, con cada vez mayores maquinarias agrícolas, la roturación de bosques, la erosión natural por medio del agua y el viento, así como la mano del hombre, han perjudicado gravemente su supervivencia. Todavía no estamos en condiciones de poder ofrecer un balance general del porcentaje total de bienes perdidos en este camino, pero sin duda sería reseñable.

Ahora bien, ¿se han tomado o se están tomando medidas al respecto? En la Comunidad Autónoma Vasca, es en este preciso instante cuando se está realizando un inventariado de todas las fortificaciones modernas. Aquí se insertan también las de cronología carlista, de modo que esperemos que este primer paso ayude a tener una primera documentación de los fuertes que hasta ahora se desconocían y se protejan como patrimonio cultural que representan.

En la Comunidad Foral de Navarra, la situación es algo más precaria. Debido a que tenemos una administración pequeña para hacerse cargo de toda la riqueza patrimonial que contiene la provincia. Dentro de la Dirección General de Cultura-Institución Príncipe de Viana, se encuentra el Servicio de Patrimonio Histórico, y dentro de él, la Sección de Arqueología. Anualmente son varios los municipios seleccionados para realizar sus cartas arqueológicas, por lo que en la actualidad son la mitad de sus municipios los que tienen los inventarios patrimoniales finalizados. Esto nos hace ver que todavía queda mucho trabajo por realizar. Por lo que muchos de los restos de las guerras carlistas todavía no han sido inscritos en el Registro de Bienes del Patrimonio Cultural de Navarra. Para el cual quedan adscritos a una de las tres clases de protección de bienes (de mayor a menor): Bienes de Interés Cultural, Bienes Inventariados, y Bienes de Relevancia Local (artículos 14-17 de la Ley Foral 14/2005, de 22 de noviembre, del Patrimonio Cultural de Navarra).

Las labores de protección en este caso, para el patrimonio al que nos referimos, no han gozado de la misma suerte que los yacimientos de cronologías anteriores. Aquí no es tanto la culpa de la propia administración, como si la falta de investigadores en esta materia que hubieran trabajado en el inventariado de las cartas arqueológicas. Solo así se explica que muchos de los fuertes en cuyos términos ya se han desarrollado el inventariado, no se encuentren clasificados. De modo que es un vacío que la administración debiera de solventar.

Por otro lado, si es verdad que en la Comunidad Foral de Navarra existen otros reductos que han quedado protegidos. En la elaboración de mi trabajo fin de máster (TFM), titulado: Arqueología de la III Guerra Carlista en el Frente de Estella (Navarra) ${ }^{4}$, se presentó el estudio de 15 fuertes entorno a la capital del carlismo (Estella), de los cuales 10 están dotados como Bien Inventariado, frente a un único caso como Bien de Relevancia Local (los restantes 4 no estaban protegidos). Este viene a ser un claro ejemplo a escala micro de cuál es la situación.

\section{DE CARA AL FUTURO}

A nivel científico, no existen trabajos que se centren en el estudio del patrimonio de las guerras carlistas, desde la arqueología. Sin embargo, esta tendencia está cambiando gracias a recientes publicaciones como la obra de Antton Arrieta Valverde (Arrieta, 2015) en cuyo trabajo se catalogan una serie de 101 fortificaciones desde el renacimiento hasta las guerras carlistas para el ámbito geográfico de la Comunidad Autónoma Vasca, Comunidad Foral de Navarra y País Vasco Francés. Se trata de un trabajo de inventariado pionero, en el cual subraya la existencia de este patrimonio bélico que ha pasado inadvertido.

4https://www.academia.edu/15965933/Arqueolog\%C3\%ADa_de_la_III_Guerra_Carlista_en_el_Frente_de_Estella_ Navarra 
Sin duda, los trabajos que más se pueden acercar desde nuestra metodología al estudio de los fuertes carlistas, provienen del blog: Hechos, Anécdotas y Relatos de las Guerras Carlistas ${ }^{5}$, en el cual su autor, Jesús Ángel Arrate, trabaja en este ámbito en sus tiempos libres. Hay que agradecerle sus periódicas entradas, ya que colabora en la recuperación de este patrimonio. Siempre intentando aportan nuevos datos, que para los interesados nunca pasan desapercibidos.

Otro aspecto importante en el que queda mucho trabajo por hacer, es la propia divulgación de los bienes. Por muchos estudios que puedan realizarse en el ámbito de la academia, tenemos la obligación de trabajar como transmisores de este saber a la ciudadanía en general. Si queremos llegar a proteger estos restos, tenemos que sociabilizarnos con los pueblos del entorno para demostrarles que unos restos que se encuentran dentro de su municipio son parte de su historia, su legado y que por tanto les pertenece. Solamente así, se puede crear una conexión entre los restos arqueológicos y la población local, pasando a ser un elemento más de la identidad propia de sus gentes. Porque hasta que no se trabaje en esa dirección, muchos restos de esta temática pasaran indiferentes ante la sociedad como un elemento extraño al que no sabrán identificarlo como parte de su cultura.

Ante esta necesidad, se espera que el fuerte de la Princesa de Asturias (Villatuerta, Navarra) sea una primera vía de sociabilización como fuerte piloto tras su primera campaña arqueológica. Su puesta en valor pasará ante un plan de divulgación que pueda comprometer a los diferentes centros educativos de la zona para que las futuras generaciones conozcan su legado contemporáneo.

Para finalizar, me gustaría dedicar estas últimas líneas a una reflexión sobre la gestión de este patrimonio y en especial a las políticas de protección desde la administración, vistas también desde una perspectiva más amplia desde la arqueología del paisaje.

En la articulación de este discurso el lector/a habrá pensado que la arqueología de las guerras carlistas se circunscribe a yacimientos únicos generalizados con el nombre de fuertes o reductos. La realidad debe traspasar el tratamiento de fuerte como unidad aislada, abriéndose en términos espaciales más amplios a conjuntos o redes de fuertes edificados en sierras con sus respectivas baterías, trincheras y campos de batalla ${ }^{6}$. En otras palabras, hablo de la necesidad de que cada resto militar no solo se pueda proteger y catalogar de forma única por las administraciones competentes, sino más bien de elevar el nivel de protección en forma conjunta a otros valores que respondan mejor a su propia naturaleza, como bien puede ser los de Conjuntos Históricos o mejor, de Paisajes Culturales (Roldán y Escribano, 2015, p. 145).

\footnotetext{
5 http://mikelatz.blogspot.com.es/

6 Para el caso tocante a los campos de batalla, no existe todavía, al menos para Navarra, ningún tipo de protección en especial. Esta casuística creo que es generalizada en España, a diferencia de lo que ocurre en Inglaterra, en donde su estudio y protección se enmarca dentro de la llamada "battlefield archaeology" o arqueología de los campos de batalla (Quesada, 2008, pp. 21-35).
} 


\section{BIBLIOGRAFÍA}

Aníbarro, S. (2006). Convento de Carmelitas de San José de la Isla (Sestao). Arkeoikuska 2005, pp. 349-352.

Aníbarro, S. (2007). Convento de Carmelitas de San José de la Isla (Sestao). Arkeoikuska 2006, pp. 375-380.

Arrieta, A. (2015). Euskal Herriko Forteak. Berpizkudetik karlismora. Tafalla.

Arrate, J. A.; Rubio, A. y Astorqui, A. (2014). Batallas de Somorrostro, 1873: viejas guerras, nuevas tecnologías. Kobie Paleoantropología, № 33, pp. 107-128.

Arrese, A. (2013). Fortificación de Atxetilun. Arkeoikuska 2012, pp. 320-321.

Astorqui, A. (2013). Propuesta metodológica para prospección en campo de batalla. Arkeoikuska 2012, pp. 214-218.

Aurrekoetxea, U. (2011). San José de la Isla. Fase III (Sestao). Arkeoikuska 2010, pp. 275-283.

Ayán, X. (2015). Guerra en la universidad. Cuando se quebraron las cristaleras de la facultad. ArkeoGazte, № 5, pp. 27-34.

Ayerbe, M. (2005). Alto de Lugaritz (DonostiaSan Sebastián). Arkeoikuska 2004, pp. 408-409.

Benito, A. M. (2003). Casco Arramendi (Rentería). Arkeoikuska 2002, pp. 156-158.

Benito, A. M. (2004). Casco Arramendi (Rentería). Arkeoikuska 2003, pp. 151-152.

Buce, J. (2012). Fuerte Zumalakarregi. Arkeoikuska 2011, pp. 321-324.

Clairac, P. (1884). Diccionario General de Arquitectura e Ingeniería. Vol. III, Madrid.

VV.AA. (2015). Arqueología del Conflicto, ArkeoGazte, № 5, pp. 9-17.
Fernández, J. (2004). Estudio Arqueológico de la muralla de la villa de Peñacerrada-Urizaharra. Arkeoikuska 2003, pp. 47-52.

González, A. (2014). Archaeology of the contemporary past. In Claire Smith (Ed.) Encyclopedia of Global Archaeology, New York, Springer, pp. 1683-1694.

González, A. (2016). Volver a las trincheras. Una arqueología de la Guerra Civil Española. Madrid.

Martinena, J. J. (2014). Del castillo al baluarte. Nuevos planteamientos de la defensa de Navarra en el siglo XVI. En Valdenebro García, José Vicente (coord.): El patrimonio fortificado pirenaico (s. XVI-XIX), Ayuntamiento de Pamplona, Pamplona, pp. 27-29.

Martínez, A. (2011). Fuerte de Arrontegi. Arkeoikuska 2010, pp. 198-201.

Martínez, A. (2013). Monte San Cristóbal (Apellániz). Arkeoikuska 2012, pp. 56-60.

Martínez, A. (2015). Monte San Bernabé (Bilbao, Erandio). Arkeoikuska 2014, pp. 266-270.

García, M. y Moraza, A. (2009). Fuerte de Ametzagaina. Arkeoikuska 2008, pp. 377-379.

Moraza, A. (2013). Fuerte de Oriamendi. Arkeoikuska 2012, pp. 278-283.

Olano, A. (1997). Prospecciones de la Edad de Hierro - Koroa (Motrico)... . Arkeoikuska 1996, pp. 160-162.

Quesada, F. (2008). La Arqueología de los campos de batalla. Notas para un estado de la cuestión y una guía de investigación. Saldvie, № 8, pp. 21-35.

Quirós, J. A. (2014). Castillo de Labastida. Arkeoikuska 2013, pp. 83-87.

Renfrew, C. y Bahn, P. (2008). Arqueología. Conceptos clave. Madrid. 
Rodríguez, J. (1986). Fuerte de San Enrique. Arkeoikuska 1985, pp. 53-55.

Rodríguez, J. (1987). Fuerte de San Enrique. Arkeoikuska 1986, p. 46.

Roldán, I. y Escribano, S. (2015). Arqueología del conflicto carlista. Valoración del legado material de varios fuertes del frente de Estella. ArkeoGazte, no 5, pp. 133-149.

Rubio, M. C. y Talavera, M. (2007). El Carlismo. Consejo Superior de Investigaciones Científicas (CSIC).

Sáez, J. A. (2014). Fortificaciones del noreste de Guipúzcoa. Siglos XVI-XX. En Valdenebro García, José Vicente (coord.): El patrimonio fortificado pirenaico (s. XVI-XIX), Ayuntamiento de Pamplona, Pamplona, pp. 100-104.
Sánchez, I. (2009). Torre de telégrafo (Quintanilla de la Rivera). Arkeoikuska 2008, pp. 133-143.

Sánchez, I. (2010). Torre de telégrafo (Quintanilla de la Rivera) Arkeoikuska 2009, pp. 109-114.

Urteaga, M. (2015). Fuerte de San Enrique. Arkeoikuska 2014, pp. 356-357. 